\title{
Proportion of Term Low Birth Weight Neonates and Their Association with Maternal Risk Factors in a Tertiary Care Hospital
}

\author{
Jesmin Jahan', Md. Shameem², Md. Nurul Amin ${ }^{3}$, Shahzadi Afroza ${ }^{4}$, Asma Sharmin ${ }^{5}$, A N M Nurul Haque Bhuiyan ${ }^{6}$
}

\begin{abstract}
Background \& objective: Term low birth weight neonate represents a heavy burden on healthcare services worldwide due to their higher incidence of morbidity and mortality than term normal weight neonates. Certain maternal factors contribute to delivering term low birth weight neonates. This study was designed to identify the proportion of term low birth weight neonates in a tertiary care hospital and their association with maternal risk factors.

Methods: This case-control study was carried out in the Department of Obstetrics \& Gynaecology, Bangabandhu Sheikh Mujib Medical University (BSMMU), Dhaka over a period of 15 months between April 2017 to June 2018. Term low birth weight $(<2500 \mathrm{gm})$ neonates delivered in Obstetrics Ward were taken as cases, while the term normal weight neonates taken from the same place were controls. A total of 80 cases and 140 controls who met the eligibility criteria were consecutively included in the study. The maternal factors (that may contribute to the development of term LBW neonates) studied were demographic characteristics, past and current obstetric histories and medical conditions or disease during the last pregnancy.

Results: In the present study the proportion of term LBW was $18.6 \%$ (80 out 430 ). Univariate analysis showed that housewives and short statured mothers carry $4(95 \% \mathrm{CI}=1.5-11.0)$ and $2.3(95 \% \mathrm{CI}=1.3-4.1)$ times higher risk of having term LBW neonates respectively. Of the obstetric characteristics, primipara and pregnant women with inadequate number of ANCs ( $<4$ visits) were more prone to have term LBW neonates with risk of having the condition being $2.0(95 \% \mathrm{CI}=1.1-3.7)$ and $2.2(95 \% \mathrm{CI}=1.0-4.9)$ times respectively. ANC visit in the $2^{\text {nd }}$ or $3^{\text {rd }}$ trimester had $4.5(95 \%$ CI $=1.0-4.9)$ times higher risk of delivering LBW neonates compared to those who made their $1^{\text {st }}$ visit in the $1^{\text {st }}$ trimester $(p<0.001)$. Mothers who maintained a narrow birth spacing $(<2$ years) had a significantly more term LBW babies with likelihood of having the condition being 3-fold (95\% CI $=1.2-7.9)$ higher than those who maintained an adequate birth spacing $(p=0.011)$. Hypertension during pregnancy tend to be significantly associated with term LBW neonates with odds of having the condition being $5.4(95 \% \mathrm{CI}=2.7-10.8)$ times greater than the normotensive ones $(p<0.001)$. However, after adjustment by binary logistic regression analysis, inadequate ANC, $1^{\text {st }}$ ANC visit in $2^{\text {nd }}$ trimester onwards, and maternal hypertension during pregnancy emerged as independent predictors of term LBW with Odds of having the condition being $3.61(95 \% \mathrm{CI}=0.65-20.17), 7.56(95 \% \mathrm{CI}=1.52-37.5)$ and $3.7(95 \% \mathrm{CI}=1.8$ - 7.9) with significance values being $p=0.032, p=0.013$ and $p<0.001$ respectively.
\end{abstract}

Conclusion: The study concluded that the mothers with inadequate ANC and $1^{\text {st }}$ ANC visit made in $2^{\text {nd }}$ or last trimester and hypertension carry much higher risk of delivering term LBW neonates compared to their respective counterparts in the same population.

\section{Authors' information:}

${ }^{1}$ Dr. Jesmin Jahan, MBBS, DGO, MS, Resident, MS (Obstetrics and Gynaecology), Bangabandhu Sheikh Mujib Medical University, Dhaka \& OSD, DG (Health)

${ }^{2}$ Dr. Md Shameem, MBBS, DCH, MD (Pediatrics), MD (Neonatology), Assistant Professor (Neonatology), Department of Pediatrics, Rajshahi Medical College, Rajshahi.

${ }^{3}$ Dr. Md Nurul Amin, Assistant Professor (Community Medicine), Rajshahi Medical College, Rajshahi \& Executive Editor, Ibrahim Cardiac Medical Journal, Ibrahim Cardiac Hospital \& Research Institude, Shahbag, Dhaka.

${ }^{4}$ Dr. Shahzadi Afruza, MBBS, MS (Obstetrics and Gynaecology), Medical Officer, Upazila Health Complex, Sonargaon, Narayanganj.

${ }^{5}$ Dr. Asma Sharmin, MBBS, MS, Resident, MS (Obstetrics and Gynaecology), Bangabandhu Sheikh Mujib Medical University, Dhaka \& OSD, DG (Health)

${ }^{6}$ Dr. A N M Nurul Haque Bhuiyan, MBBS, MD (Neonatology), Registrar ( Pediatrics), 300 Bedded Hospital, Khanpur, Narayanganj.

Correspondence: Dr. Jesmin Jahan, Phone: +880 1715113977, E-mail: shameemnova@gmail.com 


\section{INTRODUCTION:}

According to the World Health Organization (WHO), every neonate of less than 2,500 grams at birth is classified as low birth weight (LBW). In underdeveloped and developing countries the problem of LBW neonates is alarming. WHO estimates that globally about 25 million LBW neonates are born each year comprising $14 \%$ of all live-births. Nearly $93 \%$ of them are in developing countries. ${ }^{1}$ Striking variation exists in LBW prevalence within Asia: the highest rates are in South Asia and the lowest in East Asia. ${ }^{2}$ In South Asia, the problem is most acute with up to $50 \%$ of all neonates having LBW. ${ }^{2}$ Up to $25 \%$ of neonates in Pakistan are classified as LBW. ${ }^{3}$ In India $30-35 \%$ babies are LBW and more than half of these LBW are term neonates. ${ }^{4}$ The LBW rate was $22.6 \%$ and more among girls and in slums [National Low Birth Weight Survey (NLBWS), 2015]. A significant proportion of LBWs are term LBWs (IUGR). Presently more than $20 \%$ of the neonatal death in Bangladesh is due to LBW and its complications.

Compared to term appropriate for gestational age neonate, term LBW neonate has a higher incidence of morbidity and mortality. Nonetheless, in global terms, children born with LBW are 20-fold more likely to die prematurely compared to children of normal birth weight. ${ }^{7}$ Likewise, some of these children may experience more devastating, detrimental morbidity, both in the short and long term. Among these, the principal comorbidities among some severely affected term LBW such as in IUGR include congenital birth defect, perinatal asphyxia, meconium aspiration, pulmonary hemorrhage, persistent pulmonary hypertension, hypotension, hypoglycemia due to depletion of glycogen store and subcutaneous fat, hypothermia, hypocalcemia, neutropenia, polycythemia, thrombocytopenia, renal insufficiency. ${ }^{8}$ Some term LBW neonates are at higher risk for poor postnatal growth, neurologic impairment, delayed cognitive development, poor academic achievement. In adult life, some severely affected term LBW neonates such as in IUGR have a higher risk of coronary heart disease, hypertension, non-insulin dependent diabetes, stroke, obstructive pulmonary disease, renal impairment, decreased reproductive function. ${ }^{8}$ Therefore, it is clear that term LBW neonate represents a heavy burden for healthcare services worldwide. In poorer countries where fewer resources are destined for health care. In addition, the weight of a newborn at birth is an important indicator of maternal health and nutrition prior to and during pregnancy. There are numerous maternal and fetal factors contributing to LBW at term. Among maternal factors maternal undernutrition, anemia and medical illness, inadequate prenatal care, obstetric complications and maternal history of premature LBW infants, low socioeconomic status have all been reported to influence the occurrence of LBW. ${ }^{8}$ A study conducted by Nagargojeand associates suggested that mothers' education, occupation, socio-economic status, physical activity during pregnancy, sleep and rest duration, age at marriage, tobacco consumption, time of registration of pregnancy, number of antenatal visits, tetanus toxoid immunization, days of iron, folic acid and calcium supplements, all are found to be significantly associated with LBW. ${ }^{9}$ These factors operate to various extents in different environment and cultures and therefore vary from one area to another, depending upon geographic, socio-economic and cultural factors. These maternal risk-factors are biologically and socially interrelated, and most are modifiable. The morbidity and mortality of LBW can, therefore, be reduced if the maternal risk factors are detected early and managed properly.

As developing countries are experiencing rapid demographic transitions due to advancement of education, socioeconomic status and urbanization, the pattern of risk factors contributing to LBW also seems to be changing. Besides, most of the studies on LBW and its risk factors were conducted in community setting. Hospital-based study on the issue, particularly on the issue of term LBW and its risk factors is lacking. Therefore, this study was carried out in a referral tertiary hospital in the context of Bangladesh with the objective of identifying proportion of term LBW and maternal risk factors associated with it. 


\section{METHODS:}

This case-control study was conducted in the Department of Obstetrics \& Gynaecology, Bangabandhu Sheikh Mujib Medical University (BSMMU) Hospital, Dhaka over a period of 15 months between April 2017 to June 2018. Term LBW neonates delivered at the above-mentioned hospital were taken as cases, while the term normal weight neonates delivered in the same place was taken as controls. Only term neonates (delivered after 37 completed weeks to 42 completed weeks of gestation) with neonatal age $<24$ hours and mothers having complete medical record and informed consent for the study were included in the study. Preterm neonates (delivered before 37 completed weeks), Post-term neonates (after 42 completed weeks), twins were excluded from the study. Ethical Clearance was obtained from the Institutional Review Board (IRB) of Bangabandhu Sheikh Mujib Medical University (BSMMU), Dhaka.

Convenient sampling technique was employed to include the required number of patients. The outcome or dependent variable was birth weight of the neonates, while the exposure or independent variables were categorized into three groups. Maternal age, education, height, occupation was included in sociodemographic variables. Maternal anaemia, hypertension, diabetes mellitus, UTI was included in medical conditions or diseases, Past history of LBW baby, abortion, still birth, parity, birth spacing and number of ANC visits, timing of $1^{\text {st }}$ ANC visit was included in past and current obstetric history. Birth weight of every neonate was measured by an electronic weighing scale (RoHS ModelER7210 China) which is accurate to $\pm 5 \mathrm{~g}$ and was calibrated before each measurement. Weight was taken by keeping the neonate undressed. Birth weight of the neonate less than $2500 \mathrm{gm}$ was labeled as LBW (case) and birth weight from 2500 to 4000 $\mathrm{gm}$ as normal weight (control). A total of 80 cases and 140 controls who met the eligibility criteria were consecutively included in the study.

Gestational age was calculated from the menstrual history provided the dates were sure and the menstrual cycles were regular and there was no history of using oral contraceptives in the 3 months before conception. If any of the above criteria were not met to determine the gestational age, then the result of the earliest ultrasound scan if available, was used to calculate the gestational age. Data about the maternal exposure to different risk factors was recorded using a pretested questionnaire. Information was collected from mothers with face to face interviews, from medical records and by post-partum maternal examination within 72 hours of delivery and all information was cross-checked with the available records such as ANC cards, investigation reports, previous discharge report and case sheets to minimize the recall bias. Mother's standing height was measured to the nearest 0.1 $\mathrm{cm}$, making the mother stand against the measuring tape attached on a wall.

Data processing and analysis were done using SPSS (statistical package for social sciences), version 25. All the demographic, clinical and obstetric factors were then compared between the case and control groups to find the predictors of LBW. The test statistics used to analyze the data were descriptive statistics and Chi-square $\left(\chi^{2}\right)$. Categorical data were compared between groups using Chi-square $\left(\chi^{2}\right)$ Test. The risk of having low birth-weight due to a factor was calculated using Odds Ratio (OR) with its $95 \%$ confidence interval (CI). The stepwise backward regression was done to find the good-fit model which could predict the outcome of interest (birth-weight). Insignificant Chi-square produced by Hosmer and Lemeshow goodness-of-fit test was taken as evidence of good-fit model. For all analytical tests, the level of significance was set at 0.05 and $p<0.05$ was considered significant.

\section{RESULTS:}

The present case-control study aimed at determining the predictors of low birth weight included a total of 80 low birth weight (birth weight < $2500 \mathrm{gm}$ ) neonates (within 24 hours of birth) as case and 140 neonates of normal birth weight (birth weight $\geq$ $2500 \mathrm{gm}$ ) were included as control. During the study period a total of 590 mothers delivered at our 
hospital. Of them, 430 were term birth, 151 were preterm, and 9 post-term births. Of the 430 term births, 80 were low birth weight neonates giving a proportion of term LBW to be $18.6 \%$.

\section{UNIVARIATE ANALYSIS:}

Majority of the mothers of both case and control groups were $\geq 18$ years old. Maternal age was not found to be associated with low-birth weight of the neonates ( $p=0.659)$. Occupation data show that housewives tend to have term low birth weight babies more often than the service-holders ( $p=$ 0.003 ) with risk of having term LBW neonates is more than 4 times $(95 \%$ CI $=1.5-11.0)$ higher (Table I). Fifty percent of the LBW neonates had their mothers with short stature as compared to $30 \%$ of the control group ( $p=0.003)$. The risk of having LBW neonates due to short stature of mothers is 2.3 ( $95 \% \mathrm{CI}=1.3-4.1)$ times higher than the normal height mothers (Table-I). Of the obstetric characteristics, primipara was more likely to deliver LBW babies than did the multipara ( $p=0.017$ ). Pregnant women with inadequate number of ANCs ( $<4$ visits) were also prone to have term LBW babies than those with adequate ANCs $(p=0.038)$. The primipara and the mothers who made $<4$ ANC visits carry $2.0(95 \% \mathrm{CI}=1.1-3.7)$ and $2.2(95 \% \mathrm{CI}=1.0$ - 4.9) times more risk of giving birth to LBW babies respectively. Mothers who made their $1^{\text {st }}$ ANC visit in the $2^{\text {nd }}$ or $3^{\text {rd }}$ trimester had $4.5(95 \% C I=2.2-9.1$ ) times higher risk of delivering LBW neonates compared to those who made their $1^{\text {st }}$ visit in the $1^{\text {st }}$ trimester $(p<0.001)$ (Table II). Mothers who maintained a narrow birth spacing ( $<2$ years) between two consecutive births had a significantly more LBW babies than the mothers who maintained an adequate birth spacing ( 2 years or more) ( $p=$ 0.011 ) with risk of having LBW neonates in the current pregnancy was estimated to be more than 3-fold (95\% CI = 1.2 - 7.9) higher (Table II). Of the 4 medical diseases analyzed, only hypertension during pregnancy was found to significantly influence the birth weight of neonates with hypertensive women more frequently having term LBW neonates than the normotensive ones $(p<0.001)$. The risk of delivering term LBW neonates by hypertensive women being 5.4(2.7 - 10.8) times greater. Urinary tract infection (UTI) was considerably higher in the case group than that in the control group, although the difference did not turn significant ( $p=0.227$ ). (Table III).

\begin{tabular}{|c|c|c|c|c|}
\hline \multirow{2}{*}{$\begin{array}{l}\text { Demographic } \\
\text { characteristics* }\end{array}$} & \multicolumn{2}{|c|}{ Group } & \multirow[b]{2}{*}{$\mathrm{p}$-value } & \multirow{2}{*}{$\begin{array}{c}\text { OR } \\
\text { (95\% of } \\
\text { Cl of OR) }\end{array}$} \\
\hline & $\begin{array}{c}\text { Case } \\
(n=80)\end{array}$ & $\begin{array}{c}\text { Control } \\
(n=140)\end{array}$ & & \\
\hline \multicolumn{5}{|l|}{ Maternal age (years) } \\
\hline$<18$ & $5(6.2)$ & $11(7.9)$ & \multicolumn{2}{|l|}{0.659} \\
\hline$\geq 18$ & 75(93.8) & $129(92.1)$ & & \\
\hline \multicolumn{5}{|l|}{ Occupation } \\
\hline Housewife & $75(93.8)$ & $110(78.6)$ & \multirow[b]{2}{*}{0.003} & \multirow[b]{2}{*}{$4.1(1.5-11.0)$} \\
\hline Service-holder & $5(6.2)$ & $30(21.4)$ & & \\
\hline \multicolumn{5}{|l|}{ Height (cm) } \\
\hline$<150$ (short stature) & $40(50.0)$ & $42(30.0)$ & & \\
\hline$\geq 150$ (normal stature) & $40(50.0)$ & $98(70.0)$ & 0.003 & $2.3(1.3-4.1)$ \\
\hline
\end{tabular}

Figures in the parentheses denote corresponding \%. *Data were analyzed using Chi-squared $\left(\chi^{2}\right)$ Test

\section{Table II. Association between obstetric characteristics term LBW}

\begin{tabular}{|c|c|c|c|c|}
\hline \multirow{2}{*}{$\begin{array}{l}\text { Obstetric } \\
\text { characteristics* }\end{array}$} & \multicolumn{2}{|c|}{ Group } & \multirow[b]{2}{*}{$p$-value } & \multirow{2}{*}{$\begin{array}{c}\text { OR } \\
\text { (95\% of } \\
\text { Cl of OR) }\end{array}$} \\
\hline & $\begin{array}{c}\text { Case } \\
(n=80)\end{array}$ & $\begin{array}{l}\text { Control } \\
(n=140)\end{array}$ & & \\
\hline \multicolumn{5}{|l|}{ Parity } \\
\hline Primipara & $31(38.8)$ & $33(23.6)$ & \multirow{2}{*}{0.017} & \multirow{2}{*}{$2.0(1.1-3.7)$} \\
\hline Multipara & $49(61.3)$ & $107(76.4)$ & & \\
\hline \multicolumn{5}{|l|}{ Past $\mathrm{H} / \mathrm{O}$ abortion } \\
\hline Yes & $11(22.4)$ & $25(25.5)$ & \multirow{2}{*}{0.684} & \multirow{2}{*}{$0.84(0.37-1.9)$} \\
\hline No & $38(77.6)$ & $73(747.5)$ & & \\
\hline \multicolumn{5}{|l|}{ Past H/O LBW } \\
\hline Yes & $17(36.2)$ & 39(38.6) & \multirow{2}{*}{0.775} & \multirow{2}{*}{$0.9(0.4-1.8)$} \\
\hline No & $30(63.8)$ & $62(61.4)$ & & \\
\hline \multicolumn{5}{|l|}{ Past H/O still-born } \\
\hline Yes & $10(20.4)$ & $15(14.0)$ & \multirow{2}{*}{0.313} & \multirow{2}{*}{$1.5(0.7-3.8)$} \\
\hline No & $39(79.6)$ & $92(86.0)$ & & \\
\hline \multicolumn{5}{|l|}{ ANC visits } \\
\hline$<4$ & $16(20.0)$ & $14(10.0)$ & \multirow{2}{*}{0.038} & \multirow{2}{*}{$2.2(1.0-4.9)$} \\
\hline$\geq 4$ & $64(80.0)$ & $126(90.0)$ & & \\
\hline \multicolumn{5}{|l|}{ Timing of 1st visit } \\
\hline $2^{\text {nd }} \& 3^{\text {rd }}$ trimester & $28(35.0)$ & $15(10.7)$ & \multirow{2}{*}{$<0.001$} & \multirow{2}{*}{$4.5(2.2-9.1)$} \\
\hline $1^{\text {st }}$ trimester & $52(65.0)$ & $125(89.3)$ & & \\
\hline \multicolumn{5}{|l|}{ Birth spacing (yrs) } \\
\hline$<2$ & $12(24.5)$ & $10(9.3)$ & \multirow{2}{*}{0.011} & \multirow{2}{*}{$3.1(1.2-7.9)$} \\
\hline 2 or more & $37(75.5)$ & 98(90.7) & & \\
\hline
\end{tabular}

Figures in the parentheses denote corresponding \%. *Data were analyzed using Chi-squared $\left(\chi^{2}\right)$ Test 


\begin{tabular}{|c|c|c|c|c|}
\hline \multirow{2}{*}{$\begin{array}{l}\text { Medical diseases } \\
\text { during pregnancy* }\end{array}$} & \multicolumn{2}{|c|}{ Group } & \multirow[b]{2}{*}{ p-value } & \multirow{2}{*}{$\begin{array}{c}\text { OR } \\
\text { (95\% of } \\
\text { Cl of OR) }\end{array}$} \\
\hline & 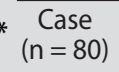 & $\begin{array}{c}\text { Control } \\
(n=140)\end{array}$ & & \\
\hline \multicolumn{5}{|l|}{ Anaemia } \\
\hline Yes & $38(47.5)$ & $58(41.4)$ & \multirow{2}{*}{0.382} & \multirow{2}{*}{$1.2(0.7-2.2)$} \\
\hline No & $42(52.5)$ & $82(58.6)$ & & \\
\hline \multicolumn{5}{|l|}{ Hypertension } \\
\hline Yes & $33(41.3)$ & $16(11.4)$ & \multirow{2}{*}{$<0.001$} & \multirow{2}{*}{$5.4(2.7-10.8)$} \\
\hline No & $47(58.8)$ & $124(88.6)$ & & \\
\hline \multicolumn{5}{|l|}{ DM } \\
\hline Yes & $10(12.5)$ & $20(14.3)$ & \multirow{2}{*}{0.710} & \multirow{2}{*}{$0.9(0.4-1.9)$} \\
\hline No & $70(87.5)$ & $120(85.7)$ & & \\
\hline \multicolumn{5}{|l|}{ UTI } \\
\hline Yes & $11(13.8)$ & $12(8.6)$ & \multirow{2}{*}{0.227} & \multirow{2}{*}{$1.7(0.7-4.1)$} \\
\hline No & $69(86.2)$ & $128(91.4)$ & & \\
\hline
\end{tabular}

Figures in the parentheses denote corresponding \%. *Data were analyzed using Chi-squared $\left(\chi^{2}\right)$ Test

\section{Binary logistic regression analysis: Model Fit}

The stepwise backward regression was done to find the good-fit model which could predict the outcome of interest (birth-weight). All the 7 maternal variables found to be significantly associated with term LBW in univariate analysis at $5 \%$ level of significance were entered into the model. Hosmer and Lemeshow goodness-of-fit test demonstrated that the model was not a good-fit-model ( $p=0.088$ ), for the correct prediction of term LBW with this model was only $38.8 \%$, although the model could correctly predict NBW in $94.4 \%$ cases (Table IV\& V). Stepwise regression model comprised with 6 variables (maternal occupation, stature, parity, number of ANC received, timing of $1^{\text {st }}$ ANC and maternal blood pressure during pregnancy) formed the best fitting model, as evidenced by insignificant Chi-square produced by Hosmer and Lemeshowgoodness-of-fit test $(p=0.350)$. The model could correctly predict the outcome in $72.7 \%$ of the cases with correct prediction of outcome of interest (LBW) being $48.8 \%$ (VI\&VII).

\begin{tabular}{|c|c|c|c|}
\hline Step & Chi-square & df & Sig. \\
\hline 1 & 12.416 & 7 & 0.088 \\
\hline
\end{tabular}

Table V. Capability of the model with 7 variables in predicting outcome

\begin{tabular}{|c|c|c|c|c|c|}
\hline & \multirow{3}{*}{\multicolumn{2}{|c|}{ Observed }} & \multicolumn{3}{|c|}{ Predicted } \\
\hline & & & \multicolumn{2}{|c|}{ Outcome } & \multirow{2}{*}{$\begin{array}{c}\text { Percentage } \\
\text { Correct }\end{array}$} \\
\hline & & & LBW & NBW & \\
\hline \multirow{3}{*}{$\begin{array}{c}\text { Step } \\
1\end{array}$} & \multirow{2}{*}{ Outcome } & LBW & 19 & 30 & 38.8 \\
\hline & & NBW & 6 & 102 & 94.4 \\
\hline & \multicolumn{2}{|c|}{ Overall Percentage } & & & 77.1 \\
\hline
\end{tabular}

Table VI. Hosmer and Lemeshow Test for model fit with 6 variables

\begin{tabular}{lccc}
\hline Step & Chi-square & df & Sig. \\
1 & 6.694 & 6 & 0.350
\end{tabular}

Table VII. Capability of the model with 6 variables in predicting outcome

\begin{tabular}{|c|c|c|c|c|c|}
\hline & \multirow{3}{*}{\multicolumn{2}{|c|}{ Observed }} & \multicolumn{3}{|c|}{ Predicted } \\
\hline & & & \multicolumn{2}{|c|}{ Outcome } & \multirow{2}{*}{$\begin{array}{c}\text { Percentage } \\
\text { Correct }\end{array}$} \\
\hline & & & LBW & NBW & \\
\hline \multirow{3}{*}{$\begin{array}{c}\text { Step } \\
1\end{array}$} & \multirow{2}{*}{ Outcome } & LBW & 39 & 41 & 48.8 \\
\hline & & NBW & 19 & 121 & 86.4 \\
\hline & \multicolumn{2}{|c|}{ Overall Percentage } & --- & --- & 72.7 \\
\hline
\end{tabular}

Table VIII demonstrates the binary logistic regression analysis of Odds Ratios for maternal characteristics/ factors likely to cause term LBW. Of the 6 variables with which the regression model was formed, inadequate ANC, $1^{\text {st }}$ ANC visit in $2^{\text {nd }}$ trimester onwards, \& maternal hypertension during pregnancy emerged as independent predictors of LBW in multivariate analyses. The mothers with inadequate ANC and $1^{\text {st }}$ ANC visit made in $2^{\text {nd }}$ or last trimester were $3.7(95 \% \mathrm{CI}=0.65-20.7)$ and $7.5(95 \% \mathrm{CI}=$ 1.5 - 37.2) times more likely to have term LBW neonates ( $p=0.032$ and $p=0.013$ respectively). Hypertensive mothers were $3.7(95 \% \mathrm{CI}=1.8$ - 7.9) more likely to have term LBW neonates compared to their normotensive counterparts $(p<0.001)$.

\begin{tabular}{|c|c|c|c|}
\hline \multirow{2}{*}{$\begin{array}{l}\text { Variables of } \\
\text { interest }\end{array}$} & \multirow{2}{*}{$\begin{array}{c}\text { Univariate } \\
\text { analysis } \\
\text { (p-value) }\end{array}$} & \multicolumn{2}{|c|}{ Multivariate analysis } \\
\hline & & $\begin{array}{c}\text { Odds Ratop } \\
\text { (95\% of } \mathrm{Cl} \text { of OR) }\end{array}$ & $\mathrm{p}$-value \\
\hline Short stature $(<150 \mathrm{~cm})$ & 0.003 & $0.60(0.32-1.14)$ & 0.234 \\
\hline Parity (Primipara) & 0.017 & $1.23(0.67-2.60)$ & 0.524 \\
\hline Occupation (Housewife) & 0.003 & $1.23(0.67-2.60)$ & 0.289 \\
\hline ANC visits $<4$ & 0.038 & $3.7(0.65-20.7)$ & 0.032 \\
\hline $\begin{array}{l}1^{\text {st }} \text { visit ANC in } \\
2^{\text {nd }} \& 3^{\text {rd }} \text { trimester }\end{array}$ & $<0.001$ & $7.5(1.5-37.2)$ & 0.013 \\
\hline $\begin{array}{l}\text { Maternal } \\
\text { hypertension }(\mathrm{mmHg})\end{array}$ & $<0.001$ & $3.7(1.8-7.9)$ & $<0.00$ \\
\hline
\end{tabular}




\section{DISCUSSION:}

Low birth weight in preterm births is quite arguable and is difficult to prevent. But low birth weight in term neonates does not stand to reason and is difficult to accept. Nevertheless, more than three-quarters $(77 \%)$ of LBW neonates in Bangladesh are growth retarded (IUGR) confirming that intrauterine growth retardation is the major cause of LBW in Bangladesh. ${ }^{10}$ In most cases the maternal factors contributing to LBW in term neonates could be prevented. This study focused on proportion of term LBWs in a tertiary hospital and its maternal factors so that preventive measures could be suggested to reduce its occurrence.

In the present study the proportion of term LBW was $18.6 \%$ (80 out 430 term births). This was quite expected as the study was carried out in BSMMU Hospital (a tertiary care hospital) where many of the pregnant women are referred from the peripheral hospitals because of high risk pregnancies. The finding is somewhat higher than a study from Pakistan $(10.6 \%)$ and much lower than a Central Indian study findings $(33 \%){ }^{11,12}$

The maternal factors (that may contribute to the development of LBW neonates) studied were demographic characteristics, past \& current obstetric histories and medical conditions or disease during the current pregnancy. Uunivariate analysis showed that housewives and short statured mothers carry $4(95 \%$ $C I=1.5-11.0)$ and $2.3(95 \% C I=1.3-4.1)$ times higher risk of having LBW neonates at term respectively. Several studies found significant association between occupation and low birth weight with housewives being more at risk of having LBW neonates..$^{13,14,15}$ It could be due to hard physical work during pregnancy, lack of rest, lack of consumption of nutritious food during pregnancy. However, several other studies did not find any significant association between maternal occupation \& low birth weight. 12,16,17

Of the obstetric characteristics, primipara and pregnant women with inadequate number of ANCs (< 4 visits) were more prone to have LBW babies with risk of having the condition being $2.0(95 \% \mathrm{CI}=1.1-3.7)$ and $2.2(95 \% \mathrm{CI}=1.0-4.9)$ times greater respectively $(p=0.017, p=0.038$ and $p<0.001)$.
Mothers who made their $1^{\text {st }}$ ANC visit in the $2^{\text {nd }}$ and $3^{\text {rd }}$ trimester had 4.5(2.2 - 9.1) times higher risk of delivering LBW neonates $(p<0.001)$. Teklehaimanotet a ${ }^{18}$ reported that burden of low birth weight deliveries in North Ethiopia was associated with inadequate ANC service utilization and unwanted pregnancy. Mumbareet $\mathrm{al}^{19}$ reported $62.4 \%$ mothers who delivered term LBW babies did not receive adequate antenatal care. Dai et $\mathrm{a}^{20}$ suggested that increasing number of prenatal visits decrease the risk of LBW which appears to be in agreement with the present study. Provision of adequate ANC is expected to reduce the risk of LBW. It creates health awareness and timely identification of complications. In the present study mothers who maintained a narrow birth spacing ( $<2$ years) had a significantly more LBW babies with likelihood of developing the condition being 3-fold (95\% CI $=1.2-7.9$ ) higher than the mothers who maintained an adequate birth spacing ( $p$ $=0.011$ ). Of the 4 medical diseases analyzed, only hypertension during pregnancy tend to be significantly associated with LBW neonates with odds of having the condition being $5.4(2.7-10.8)$ times greater than in the normotensive ones $(p<0.001)$.

But after adjustment by binary logistic regression analysis, only three maternal factors (inadequate ANC, $1^{\text {st }}$ ANC visit in $2^{\text {nd }}$ trimester or onwards, and maternal hypertension during pregnancy) emerged as independent predictors of term LBW. The mothers with inadequate ANC and $1^{\text {st }}$ ANC visit made in $2^{\text {nd }}$ or last trimester were $3.7(95 \% \mathrm{CI}=0.65-20.7)$ and 7.5(95\% CI $=1.5-37.2)$ times more likely to have LBW neonates $(p=0.032 \& p=0.013)$ respectively. Hypertensive mothers were $3.7(95 \% \mathrm{CI}=1.8-7.9)$ times more prone to have LBW neonates compared to their normotensive counterparts $(p<0.001)$. Consistent with these findings, Mumbare and associates in a study similar to the present study observed birth spacing $<36$ months, maternal height $\leq 145 \mathrm{~cm}$, pre-delivery weight $\leq 55 \mathrm{~kg}$, pregnancy weight gain $\leq 6 \mathrm{~kg}$, exposure to tobacco, inadequate antenatal care, maternal hypertension, low socio-economic status, maternal anemia and less maternal education to be associated with the delivery of a low birth weight infants. ${ }^{19}$ Conditional logistic 
regression analysis showed that significant risk factors associated with low birth weight were inadequate ANC (OR = 4.98, 95\% CI: 2.64 to 9.39), maternal weight before delivery $\leq 55 \mathrm{~kg}(\mathrm{OR}=4.81$, $95 \% \mathrm{CI}: 2.53$ to 9.15 ) and height $\leq 145 \mathrm{~cm}$ (OR-4.13, 95\% CI-2.04 to 8.37) which compare well with our study findings.

Khan et $\mathrm{al}^{11}$ found low socio-economic status, primiparity, short maternal height and inadequate antenatal care to be associated with low birth weight at term. Bhaskaret $\mathrm{al}^{21}$ found maternal height, iadequate ANC visits, time of first antenatal care visit, and hypertension as the significant predictors of LBW which are all consistent with the findings of the present study. Although several studies found strong association of term LBW with anaemia, 11,12,14,19,22 the present study failed to demonstrate such association.

Data presented highlight a number of risk factors relevant to term low birth weight. These findings provide insights into the health workforce, health policies, health information and community mobilization relevant to prevention of term low birth weight (IUGR). The information provided here can be used to identify the most important risk factors to target and gaps in care in order to identify and implement solutions for improved outcomes. Finally, like any other scientific study, the present study is not without limitation. Certain variables like number of ANC visits made, timing of $1^{\text {st }}$ ANC visit were subjectively evaluated which may either be underestimated or overestimated due to recall bias. Therefore, caution is advised to interpret these data, particularly in case of generalization of the findings to reference population. Certain maternal factors like pre-pregnancy weight, weight gain during pregnancy, nature of work during pregnancy (light work or hard labor) and food behavior which were though relevant to this study were not feasible to be included.

\section{Conclusion:}

From the findings of the study it can be concluded that three maternal factors - inadequate ANC, $1^{\text {st }}$ ANC visit in $2^{\text {nd }}$ or $3^{\text {rd }}$ trimester and maternal hypertension during pregnancy are the independent predictors of term LBW. The mothers with inadequate
ANC and $1^{\text {st }}$ ANC visit made in $2^{\text {nd }}$ or last trimester and hypertension carry much higher risk of delivering term LBW compared to their respective counterparts in the same population. Controlling for maternal risk factors for term LBW neonates will go a long way in reducing the incidence of term LBW neonates.

\section{References:}

1. Park K, Text book of preventive \& social medicine. $21^{\text {st }}$ Edition, Banarasidas Bhanot publishers. Jabalpur India 2011:494.

2. Rizvi SA, Hatcher J, Jehan I, Qureshi R.Maternal risk factors associated with low birth weight in Karachi: a case- control study. East Mediterr Health J2007; 13:1343-52.

3. Khan N, Jamal M, 'Maternal risk factors associated with low birth weight'. Journal of Physicians and Surgeons of Pakistan 2003;13:25-8.

4. WHO, Bridging the gaps, The World health report, Report of the Director General 1995.

5. WHO, Country, regional and global estimates 2005 .

6. Goldenberg RL, Culhane JF, Low birth weight in the United States. Am J Clin Nutr 2007;85:584S-90S.

7. WHO, The world health report 2005. Make every mother and child count. The greatest risks to life are in its beginning 2005:79-81.

8. Cloherty JP, Eichenwald EC, Hansen AR et al, Manual of neonatal care, Philadelphia, USA. 2012.

9. Nagargoje MM, Chaudhary SS, Deshmukh JS et al, A case-control study of risk factors for low birth weight in Nagpur city of Maharashtra. Ind $\mathrm{J}$ Comm Health 2010;22(2):4-7.

10. National low birth weight survey of Bangladesh 2003-04, UNICEF.

11. Khan A, Nasrullah FD, JaleelR ,Frequency and risk factors of low birth weight in term pregnancy. Pak J Med Sci 2016;15(12):39-41.

12. Kumar V,Magnitude and correlates of lowbirth weight at term in rural wardha. Online Journal of Health and Allied Sciences 2016;15(1):1-5.

13. Ahmed P, Jaakkola JJ, Maternal occupation and adverse pregnancy outcomes: A Finnish population-based study. Occup Med (Lond) 2007;57(6):417-23.

14. Anand K, Garg BS, A study of factors affecting low birth weight. Indian J Community Med 2000;25(2):57-62.

15. Nair NS, Rao RSP, Chandrashekar S, Das A, Bhatt HV, Socio-demographic and maternal determinants of low 
birth weight: A multivariate approach. Indian J Pediatr 2000;67(1):9-14.

16. Siza JE, Risk factors associated with low birth weight of neonates among pregnant women attending a referral hospital in Northern Tanzania. Tanzan J Health Res 2008;10(1):1-8.

17. Roudbari M, Yaghmari M, Sochili M, Prevalence and risk factors of low birth weight infants in Zahanden, Islamic Republic of Iran. East Mediterr Health J 2007;13(4): 834-45.

18. Teklehaimanot $N$, Hailu $T$, Assefa $H$, Prevalence and factors associated with low birth weight in axum and laelaymaichew districts, North Ethiopia: a comparative cross sectional study. International Journal of Nutrition and Food Sciences 2009;3(6):560-6.

19. Mumbare SS, Maindarkar G, Darade R, Yenge S, Tolani MK, Patole K.Maternal risk factors associated with term low birth weight neonates: A matched-pair case control study. Indian pediatrics 2012;49(1):25-8.
20. Dai LL, Mao YY, Luo XM, Shen YP, Prenatal Care in Combination with Maternal Educational Level Has a Synergetic Effect on the Risk of Neonatal Low Birth Weight: New Findings in a Retrospective Cohort Study in Kunshan City, China. PLOS ONE 2014;9(11):1-13, e113377. doi: 10.1371/ journal.pone.0113377

21. Bhaskar RK, Deo KK, Neupane U, Bhaskar SC, Yadav $\mathrm{BK}$, Pokharel HP et al, A case control study on risk factors associated with low birth weight babies in eastern Nepal, International Journal of Pediatrics 2015;2015:1-8.

22. Kalady MA, Sunilbala K, Singh YT, Singh N, Mawphlang IL ,Ahmed MS, Effect of Maternal Anemia on Birth Weight of Term Babies in A Tertiary Care Hospital, Manipur. Journal of Dental and Medical Sciences 2016;52(2):87-91. DOI: 10.9790/0853-1512063941. 